\title{
Breast milk vitamin B12 concentration and incidence of diarrhea and respiratory infections among infants in urban Tanzania: a prospective cohort study
}

\author{
Omar N. Lweno ${ }^{1 *}$, Christopher R. Sudfeld ${ }^{2,3}$, Ellen Hertzmark ${ }^{3,4}$, Karim P. Manji ${ }^{5}$, Anne Marie Darling ${ }^{3}$
} and Wafaie W. Fawzi ${ }^{2,3}$

\begin{abstract}
Objective: A recent trial of vitamin B12 supplementation among Indian children 6-30 months found no effect on the incidence of diarrhea and respiratory infections. These results differ with studies in adults that showed improvement of the immune response following treatment with vitamin B12. We sought to determine how the adequacy of vitamin B12 concentrations in breast milk could act as immune modulator and protect against the incidence of diarrhea and respiratory infections of children up to 18 months in urban Tanzania.

Results: A prospective cohort study was undertaken to determine the association of breast milk vitamin B12 concentration with the incidence of acute respiratory infection and diarrhea among infants in urban Tanzania. A random sample of 491 women enrolled in a trial of multivitamins provided milk for B12 analysis at or around 6 weeks postpartum. Of 491 women, 345 had breast milk vitamin B12 inadequacy (<310 pmol/L). Using generalized estimating equations, we found no overall association of milk vitamin B12 concentration with incident diarrhea and acute respiratory infections in infants. Studies measuring longitudinal changes of breast milk B12 concentration over time are needed to clarify the role of breast milk vitamin B12 in childhood infections.
\end{abstract}

Keywords: Breast milk, Vitamin B12, Childhood infections

\section{Introduction}

Vitamin B12 deficiency is common among women and infants in low and middle-income countries, partially due to inadequate intake and limited diet diversity [1]. Infants who develop vitamin B12 deficiency due to inadequate intake from breast milk or other sources may be at increased risk for infections, growth deficits, and neurodevelopmental delays [2]. A recent clinical trial in India reported that vitamin B12 supplementation among

\footnotetext{
*Correspondence: olweno@ihi.or.tz

${ }^{1}$ Ifakara Health Institute, Bagamoyo Research and Training Center, Bagamoyo, Tanzania

Full list of author information is available at the end of the article
}

children 6-30 months of age had no effect on the incidence of diarrhea or acute lower respiratory tract infections [3].

Previous studies in adults have reported enhancement of cellular immune response following vitamin B12 supplementation [4] and restoration of both cellular and humoral immune responses following vitamin B12 treatment [5]. As a result, maternal breast milk vitamin B12 levels may be an infant immune modulator and determinant of infectious disease risk for breastfeeding infants.

We tested the hypothesis that greater concentration of vitamin B12 in breast milk is protective against the incidence of childhood diarrhea and respiratory infections 
in a cohort of mother and infant pairs in Dar es Salaam, Tanzania.

\section{Main text Methods}

A random sample of 500 women who participated in a randomized trial of multivitamin supplementation [6] was selected for vitamin B12 breast milk analysis. Breast milk samples were collected at or around the 6th-week postpartum (mean $=5.4$ weeks, $\mathrm{SD}=0.5)$ visit between March 2003 and February 2005. They were stored at minus 80 degrees centigrade in a biobank at the Muhimbili University of Health and Allied Sciences (MUHAS). The material transfer agreement (MTA) between the MUHAS and the Harvard T.H. Chan School of Public Health (HSPH) was signed and approved by the chair of the medical research coordinating committee (MRCC) in Tanzania before the shipment of samples. Samples were shipped using dry ice from Tanzania to the USDA Western Human Nutrition Research Center in Davis, California for analysis by competitive chemiluminescent enzyme immunoassay [7]. Three samples were too small for analysis, four samples were collected more than 8 weeks after delivery, and two could not be linked to randomized study participants leaving 491 samples.

Breast milk vitamin B12 concentration at or above $310 \mathrm{pmol} / \mathrm{L}$ was considered to define adequacy [8].

Child morbidity was assessed once a month from birth to 18 months of age. Maternal reports about the occurrence of diarrhea and respiratory infections were recorded by study nurses during the monthly visit. The constellation of the following symptoms of cough, difficulties in breathing and any fever not exceeding 7 days was used to define acute respiratory infection whilst diarrhea was defined by the passage of more than three loose stools per day $(24 \mathrm{~h})$.

Log-binomial models were used to determine the relative risk of acute respiratory infection during follow-up comparing those with or without adequate vitamin B12 in their breast milk. Log-poisson models were used to compare incidence rates of diarrhea between those with adequate vitamin B12 levels in breast milk (reference group) and those with inadequate vitamin B12 leves in breast milk (exposed group). Additionally, we investigated the relationship between the risk of diarrhea and acute respiratory infection across the quartiles of vitamin B12 concentration in breast milk categorized as Q1 (less than $169 \mathrm{pmol} / \mathrm{L}), \mathrm{Q} 2$ (169-205 pmol/L), Q3 (206$338 \mathrm{pmol} / \mathrm{L}$ ), and Q4 (more than or equal to $339 \mathrm{pmol} / \mathrm{L}$ ). Quartile 4 was used as a reference group in comparison to the other quartiles of breast milk vitamin B12 concentration. Generalized estimating equations (GEE) were used to account for repeated measurements of acute respiratory infection and diarrhea variables in infants. In multivariable models, all dichotomous and continuous covariates with $p$ value less than 0.20 or categorical covariates with p-value for an individual level compared with a reference level less than 0.20 were used to fit a multivariable model. The resulting multivariable model for acute respiratory infection included child gender, birth weight, and maternal hemoglobin at 6 weeks postpartum. The multivariable model for diarrhea included treatment arm, maternal education, the Filmer-Pritchett wealth score, baseline BMI, and maternal hemoglobin at 6 weeks..

\section{Results}

Characteristics of the study population are presented in Table 1. Out of the 491 women included in the study, $345(70 \%)$ had less than adequate vitamin B12 in breast milk $(<310 \mathrm{pmol} / \mathrm{L})$. Vitamin B12 concentration in breast milk less than adequate intake $(<310 \mathrm{pmol} / \mathrm{L})$ at the 6th week postpartum was not associated with the risk of incident respiratory infection $(\mathrm{RR}=1.01,95 \%$ CI $0.90-1.14)$ or diarrheal disease (IRR $=0.95,95 \%$ CI $0.86-1.05$ ) in infants (Table 2). There was also no association of quartiles of vitamin B12 concentration in breast milk with the incidence of acute respiratory infection (p-values for trend $>0.05$ ). The risk of diarrhea was lower among infants born to mothers whose breast milk vitamin B12 concentration was categorized in the first quartile (IRR $=0.85,95 \%$ CI $0.75-0.97)$ and the third quartile (IRR $=0.95,95 \%$ CI 0.84-1.07) but not the second quartile (IRR $=1.02,95 \%$ CI 0.91-1.15) when compared to the reference group of fourth quartile (Table 2). However, the trend test was not statistically significant ( $\mathrm{p}$-values for trend $>0.05)$.

\section{Discussion}

Our study found a high proportion of women (70\%) with less than adequate concentration of vitamin B12 in breast milk in urban Tanzania. It was slightly lower than that reported in a study conducted in Kenya (89\%) where breast milk samples were collected at 6 months postpartum and Cambodia (75\%) where breast milk was collected at 12 months postpartum and the cut-off value to define adequacy was $365 \mathrm{pmol} / \mathrm{L}[8,9]$.

In this study, we found no overall association of breast milk vitamin B12 status with incident diarrhea and acute respiratory infections both as a binary exposure (adequate and inadequate) or expressed as quartiles. Our results are similar to results from India by Strand and colleagues that found no association of infant vitamin B12 deficiency with incidence of respiratory tract infection [10]. 
Table 1 Descriptive characteristics of mothers by breastmilk vitamin B12 status at 6 weeks postpartum in Tanzania

\begin{tabular}{|c|c|c|c|}
\hline Characteristic & Descriptive statistics & $\mathrm{B} 12<310 \mathrm{pmol} / \mathrm{L}(\mathrm{N}=345)$ & $\begin{array}{l}B 12>=310 \mathrm{pmol} / \mathrm{L} \\
(\mathrm{N}=146)\end{array}$ \\
\hline \multicolumn{4}{|l|}{ Treatment arm } \\
\hline Placebo & $\mathrm{N}$, column \% & $180(52.2)$ & $64(43.8)$ \\
\hline Multivitamins & $\mathrm{N}$, column $\%$ & $165(47.8)$ & $82(56.2)$ \\
\hline Maternal age in years & Mean, SD & $25.9(5.1)$ & $25.5(5.0)$ \\
\hline \multicolumn{4}{|l|}{ Maternal age (years) } \\
\hline$<20$ & $\mathrm{~N}$, column \% & $49(16.3)$ & $24(18.3)$ \\
\hline $20-24$ & $\mathrm{~N}$, column $\%$ & $89(29.7)$ & $36(27.5)$ \\
\hline $25-29$ & $\mathrm{~N}$, column $\%$ & $85(28.3)$ & $40(30.5)$ \\
\hline$\geq 30$ & $\mathrm{~N}$, column \% & $75(25.0)$ & $29(22.1)$ \\
\hline \multicolumn{4}{|l|}{ Maternal education (years) } \\
\hline $0-4$ & $\mathrm{~N}$, column \% & $39(11.4)$ & $16(11.1)$ \\
\hline $5-7$ & $\mathrm{~N}$, column $\%$ & $219(63.9)$ & $91(63.2)$ \\
\hline $8-11$ & $\mathrm{~N}$, column \% & $64(18.7)$ & $22(15.3)$ \\
\hline $12+$ & $\mathrm{N}$, column $\%$ & $21(6.1)$ & $15(10.4)$ \\
\hline Maternal BMI at baseline $\left(\mathrm{kg} / \mathrm{m}^{2}\right)$ & Mean, SD & $24.8(4.1)$ & $24.5(4.1)$ \\
\hline \multicolumn{4}{|l|}{ Maternal BMl categories $\left(\mathrm{kg} / \mathrm{m}^{2}\right)$} \\
\hline Less than 22.0 & $\mathrm{~N}$, column \% & $77(24.3)$ & $43(32.3)$ \\
\hline $22.0-24.9$ & $\mathrm{~N}$, column \% & $109(34.4)$ & $38(28.6)$ \\
\hline $25.0-29.9$ & $\mathrm{~N}$, column \% & $101(31.9)$ & $37(27.8)$ \\
\hline 30 or more & $\mathrm{N}$, column \% & $30(9.5)$ & $15(11.3)$ \\
\hline Maternal $\mathrm{Hb}$ at 6 weeks (gm/dL) & Mean, SD & $12.0(1.6)$ & $12.5(1.8)$ \\
\hline \multicolumn{4}{|c|}{ Maternal $\mathrm{Hb}$ categories at 6 weeks ( $\mathrm{gm} / \mathrm{dL})$} \\
\hline Less than 8.5 & $\mathrm{~N}$, column \% & $13(3.8)$ & $2(1.4)$ \\
\hline $8.5-10.9$ & $\mathrm{~N}$, column \% & $58(16.8)$ & $20(13.7)$ \\
\hline 11.0 or more & $\mathrm{N}$, column \% & $269(78.0)$ & $121(82.9)$ \\
\hline \multicolumn{4}{|l|}{ Infant gender } \\
\hline Female & $\mathrm{N}$, column \% & $165(47.8)$ & $76(52.4)$ \\
\hline Male & $\mathrm{N}$, column \% & $180(52.2)$ & $69(47.6)$ \\
\hline Birth weight (kg) & Mean, SD & $3.2(0.5)$ & $3.1(0.5)$ \\
\hline \multicolumn{4}{|l|}{ Birth weight categories $(\mathrm{kg})$} \\
\hline$\leq 2.0$ & $\mathrm{~N}$, column \% & $7(2.1)$ & $6(4.3)$ \\
\hline $2.001-2.499$ & $\mathrm{~N}$, column \% & $11(3.3)$ & $7(5.0)$ \\
\hline$\geq 2.5$ & $\mathrm{~N}$, column \% & $320(94.7)$ & $127(90.7)$ \\
\hline
\end{tabular}

Our results are similar to a cross-sectional study in Nepal that reported a high prevalence of vitamin B12 deficiency among children with acute diarrhea enrolled in a zinc supplementation trial [11]. They found no significant association of child plasma cobalamin and folate with the duration and numbers of loose or watery stool although the use of plasma samples limit direct comparison to breast milk samples. We cannot attribute causality of acute diarrhea to cobalamin or folate deficiency because of the cross-sectional design of the Nepal study, however, it highlights the need of considering how plasma levels of the two micronutrients are affected by intake from breast milk and other dietary sources during infancy. Clinical studies that measure absorption of vitamin B12 from breast milk are required to better understand its effect on plasma vitamin B12 and the status of its functional biomarkers.

\section{Conclusion}

Overall, the proportion of women with concentrations indicating inadequate vitamin B12 in their breast milk is high in urban Tanzania. We found no association of vitamin B12 concentration in breast milk with incidence of diarrhea and respiratory infections among Tanzanian infants. Prospective studies that measure the longitudinal variation of breast milk B12 concentration and the incidence of childhood infections are needed to clarify its role in childhood infections. 
Table 2 Breast milk vitamin B12 as a predictor of ARI and diarrhea among infants in Urban Tanzania

\begin{tabular}{|c|c|c|c|c|c|}
\hline & & \multicolumn{2}{|l|}{ Univariate analysis } & \multicolumn{2}{|l|}{ Multivariate analysis $^{a}$} \\
\hline & & Relative risk (95\% Cl) & P-value & Relative risk $(95 \% \mathrm{Cl})$ & P-value \\
\hline \multicolumn{6}{|l|}{ Acute respiratory infection } \\
\hline \multicolumn{6}{|l|}{ Breast milk vitamin B12 status } \\
\hline Adequate intake ( $\geq 310 \mathrm{pmol} / \mathrm{L})$ & 146 & Ref & & Ref & \\
\hline Less than adequate intake (<310 pmol/L) & 345 & $1.04(0.93,1.17)$ & 0.49 & $1.01(0.90,1.14)$ & 0.85 \\
\hline \multicolumn{6}{|l|}{ Quartiles of breast milk vitamin B12 (pmol/L) } \\
\hline Q4 (more than or equal 339) & 122 & Ref & 0.95 & Ref & 0.75 \\
\hline Q3 (206-338) & 125 & $1.04(0.90,1.20)$ & & $1.01(0.87,1.17)$ & \\
\hline Q2 (169-205) & 127 & $0.95(0.82,1.11)$ & & $0.93(0.80,1.08)$ & \\
\hline Q1 (less than 169) & 116 & $1.04(0.89,1.20)$ & & $1.00(0.86,1.16)$ & \\
\hline \multirow[t]{2}{*}{ Diarrheal disease } & & \multicolumn{2}{|l|}{ Univariate analysis } & \multicolumn{2}{|c|}{ Multivariate analysis $(\mathrm{N}=471)^{\mathrm{b}}$} \\
\hline & & $\begin{array}{l}\text { Incidence rate ratio }(95 \% \\
\mathrm{Cl})\end{array}$ & P-value & $\begin{array}{l}\text { Incidence rate ratio }(95 \% \\
\mathrm{Cl})\end{array}$ & p-value \\
\hline \multicolumn{6}{|l|}{ Breast milk vitamin B12 status } \\
\hline Adequate intake ( $\geq 310 \mathrm{pmol} / \mathrm{L})$ & 139 & Ref & & Ref & \\
\hline Less than adequate intake (<310 pmol/L) & 325 & $0.99(0.90,1.08)$ & 0.77 & $0.95(0.86,1.05)$ & 0.30 \\
\hline \multicolumn{6}{|l|}{ Quartiles of Breast milk vitamin B12 (pmol/L) } \\
\hline Q4 (more than or equal 339) & 117 & Ref & 0.54 & Ref & 0.06 \\
\hline Q3 (206-338) & 115 & $0.94(0.83,1.06)$ & & $0.95(0.84,1.07)$ & \\
\hline Q2 (169-205) & 123 & $1.07(0.95,1.21)$ & & $1.02(0.91,1.15)$ & \\
\hline Q1 (less than 169) & 109 & $0.91(0.80,1.03)$ & & $0.85(0.75,0.97)$ & \\
\hline
\end{tabular}

Estimates and p-values based on generalized estimating equations (GEE) with the log link and the binomial distribution, with a working exchangeable correlation structure

a Multivariable model include child sex, birth weight and linear maternal hemoglobin at 6 weeks postpartum

b Multivariable model include maternal treatment arm, maternal education, maternal wealth score, baseline BMI, and linear maternal hemoglobin at 6 weeks postpartum. Estimates and p-values based on generalized estimating equations (GEE) with the log link and the Poisson distribution, with an independent correlation structure

\section{Limitations}

Our study had several limitations. First, we assessed vitamin B12 concentration at a single time-point which does not allow for assessment of changes in breast milk composition over time. In addition, we did not have information on the concentrations of other micronutrients in breast milk [12], maternal antibodies, the frequency of breastfeeding and gut microbiota [13] which may also influence the incidence of diarrhea and respiratory infections. Other residual confounders that should be investigated in future studies of micronutrient concentration and adequacy in breast milk include breast milk volume, infant micronutrient intake from breast milk, infant weight, infant age, parity, and micronutrient status of the mothers during pregnancy [14]. Further, no information was available on diarrhea severity, which may modify its relationship to B12 status [15]. In addition, we measured incidence of diarrhea and respiratory infections using maternal report which may have led to some degree of misclassification.

\section{Abbreviations}

Al: Adequate intake; BMI: Body mass index; Cl: Confidence interval; GEE: Generalized estimating equations; GID: Global infectious disease; Hb: Hemoglobin; HSPH: Harvard T.H. Chan School of Public Health; IRB: Institutional review board; Kg: Kilogram; PNS: Perinatal study; MRCC: Medical Research Coordinating Committee; MTA: Material Transfer Agreement; MUHAS: Muhimbili University of Health and Allied Sciences; NatHREC: National Health Research Ethics Committee; NIH: National Institute of Health; NIMR: National Institute for Medical Research; RR: Relative risk; USDA: United States Department of Agriculture.

\section{Acknowledgements}

We are thankful for the U.S. National Institute of Health, Fogarty International Center for supporting the training program. We are also grateful to all participants in the Perinatal (PNS) study.

\section{Authors' contributions}

ONL conducted statistical analysis and wrote the manuscript. CRS reviewed the study design, statistical analysis, and manuscript. EH supervised the statistical analysis, reviewed the manuscript. KPM and AMD supervised data gathering, data entry, and implementation of primary study. WWF supervised the primary and secondary study and reviewed the manuscript. All authors read and approved the final manuscript.

\section{Funding}

This work was financially supported by the GID training program sponsored by the U.S. National Institute of Health $(\mathrm{NIH})$ Fogarty International Center. 


\section{Availability of data and materials}

The datasets used and analyzed during the current study are not publicly available. However, the datasets are available from the authors upon reasonable request and with permission of sponsor.

\section{Ethics approval and consent to participate}

Informed consent (written) or by means of a thumbprint in case of illiterate participants was obtained in the primary study i.e. trial of multivitamins in HIV negative women in Tanzania (NCT00197548). They also consented for storage and future analyses of samples for ancillary studies. The ethical approval to perform secondary analysis of data was granted by the National Health Research Ethics Committee (NathREC) in Tanzania (NIMR/HQ/R.8a/Vol.IX/2649) and the Harvard T.H. Chan School of Public Health Human Subjects Committee in Boston, MA. The IRB approval number was 10433.

\section{Consent for publication}

Not applicable.

\section{Competing interests}

The authors declare that they have no competing interests.

\section{Author details}

${ }^{1}$ Ifakara Health Institute, Bagamoyo Research and Training Center, Bagamoyo, Tanzania. ${ }^{2}$ Departments of Nutrition, Harvard T.H. Chan School of Public Health, Boston, MA, USA. ${ }^{3}$ Departments of Global Health and Population, Harvard T.H. Chan School of Public Health, Boston, MA, USA. ${ }^{4}$ Departments of Epidemiology, Harvard T.H. Chan School of Public Health, Boston, MA, USA

${ }^{5}$ Muhimbili University of Health and Allied Sciences, Dar es Salaam, Tanzania.

Received: 21 January 2020 Accepted: 10 March 2020

Published online: 18 March 2020

\section{References}

1. Smith ER, Shankar AH, Wu LS, Aboud S, Adu-Afarwuah S, Ali H, et al. Modifiers of the effect of maternal multiple micronutrient supplementation on stillbirth, birth outcomes, and infant mortality: a meta-analysis of individual patient data from 17 randomised trials in low-income and middle-income countries. Lancet Global Health. 2017;5(11):e1090-100.

2. Dror DK, Allen LH. Effect of vitamin B12 deficiency on neurodevelopment in infants: current knowledge and possible mechanisms. Nutr Rev. 2008;66(5):250-5.

3. Taneja S, Strand TA, Kumar T, Mahesh M, Mohan S, Manger MS, et al. Folic acid and vitamin B-12 supplementation and common infections in 6-30-mo-old children in India: a randomized placebo-controlled trial. Am J Clin Nutr. 2013;98(3):731-7.
4. Tamura J, Kubota K, Murakami H, Sawamura M, Matsushima T, Tamura T, et al. Immunomodulation by vitamin B12: augmentation of CD8 + T lymphocytes and natural killer (NK) cell activity in vitamin B12-deficient patients by methyl-B12 treatment. Clin Exp Immunol. 1999;116(1):28-32.

5. Erkurt MA, Aydogdu I, Dikilitaş M, Kuku I, Kaya E, Bayraktar N, et al. Effects of cyanocobalamin on immunity in patients with pernicious anemia. Med Princ Pract. 2008:17(2):131-5.

6. Fawzi WW, Msamanga Gl, Urassa W, Hertzmark E, Petraro P, Willett WC, et al. Vitamins and perinatal outcomes among HIV-negative women in Tanzania. New Engl J Med. 2007;356(14):1423-31.

7. Hampel D, Shahab-Ferdows S, Domek JM, Siddiqua T, Raqib R, Allen LH. Competitive chemiluminescent enzyme immunoassay for vitamin B12 analysis in human milk. Food Chem. 2014;153:60-5.

8. Williams AM, Chantry CJ, Young SL, Achando BS, Allen LH, Arnold BF, et al. Vitamin B-12 concentrations in breast milk are low and are not associated with reported household hunger, recent animal-source food, or vitamin B-12 intake in women in rural Kenya. J Nutr Community Int Nutr. 2016;146(5):1125-31.

9. Chebaya P, Karakochuk C, March K, Chen N, Stamm R, Kroeun H, et al. Correlations between maternal, breast milk, and infant vitamin B12 concentrations among mother-infant dyads in Vancouver, Canada and Prey Veng, Cambodia: an exploratory analysis. Nutrients. 2017;9(3):270.

10. Strand TA, Taneja S, Bhandari N, Refsum H, Ueland PM, Gjessing HK, et al. Folate, but not vitamin B-12 status, predicts respiratory morbidity in north Indian children. Am J Clin Nutr. 2007;86(1):139-44.

11. Ulak M, Chandyo RK, Adhikari RK, Sharma PR, Sommerfelt H, Refsum H, et al. Cobalamin and folate status in 6 to 35 months old children presenting with acute diarrhea in Bhaktapur, Nepal. PLOS ONE. 2014;9(3):e90079.

12. Maggini S, Wintergerst ES, Beveridge S, Hornig DH. Selected vitamins and trace elements support immune function by strengthening epithelial barriers and cellular and humoral immune responses. $\mathrm{Br} J$ Nutr. 2007;98(S1):S29-35.

13. LeBlanc JG, Milani C, de Giori GS, Sesma F, van Sinderen D, Ventura M. Bacteria as vitamin suppliers to their host: a gut microbiota perspective. Curr Opin Biotechnol. 2013;24(2):160-8.

14. Daniels L, Gibson RS, Diana A, Haszard JJ, Rahmannia S, Luftimas DE, et al. Micronutrient intakes of lactating mothers and their association with breast milk concentrations and micronutrient adequacy of exclusively breastfed Indonesian infants. Am J Clin Nutr. 2019;110(2):391-400.

15. Giannattasio A, Guarino A, Vecchio AL. Management of children with prolonged diarrhea. F1000 Res. 2016;5:206

\section{Publisher's Note}

Springer Nature remains neutral with regard to jurisdictional claims in published maps and institutional affiliations.
Ready to submit your research? Choose BMC and benefit from:

- fast, convenient online submission

- thorough peer review by experienced researchers in your field

- rapid publication on acceptance

- support for research data, including large and complex data types

- gold Open Access which fosters wider collaboration and increased citations

- maximum visibility for your research: over $100 \mathrm{M}$ website views per year

At $\mathrm{BMC}$, research is always in progress.

Learn more biomedcentral.com/submissions 